\title{
Emerging clean energy markets are drivers for solar and wind industries
}

\author{
Marina Faminskaya ${ }^{1 *}$, Elena Potekhina $^{1}$ \\ ${ }^{1}$ Faculty of Information Technology, Russian State Social University, 4 Wilhelm Pik str., Moscow, \\ 129226, Russian Federation
}

\begin{abstract}
Emerging markets are rapidly developing and outperforming developed markets in terms of onshore wind and solar power. Moreover, emerging markets are now getting drivers for the enhancement of global renewable energy as they are seen as territories with the greatest potential for expansion of wind and solar capacities. This study aims to investigate the casual links between financial investments by gas and oil giants and long-term vision around clean energy. We analysed various reports on procurement tools used by corporations, purchasing renewable energy. This gave us an idea about the availability and frequent usage of different instruments employed around world. The empirical results show that state support and policy development both have positive impact on state and private investments in the long run. The influence of energy development is more evident in emerging clean energy markets. The findings of the this study suggest that as renewable energy targets price and performance parity with traditional sources around the world, and is getting able to improve grid efficiency thus strengthening its competitive edge with new technologies, the hurdles to its adoption are disappearing.
\end{abstract}

\section{Introduction}

The solar and wind industries and markets initially emerged in developed countries, which we define as the 33 high-income OECD member countries, though over the time, these industries have shifted to emerging markets, i.e. all less developed countries. Emerging markets outpaced developed markets in onshore wind power growth in 2013, and later in 2016 in photovoltaic growth. These areas accounted for $63 \%$ of all new global investments in renewable energy sources in 2017, which widened the gap with developed countries to record levels. Currently, the total capacity of such facilities exceeds the indicator for the developed world [1,2]. Emerging markets declined the cost of renewable energy, which allowed them to bypass developed countries in terms of deployment of renewable energy sources, reduce the volume of carbon intensive developments and innovate in such a way that those initiatives are useful both for emerging and developed markets.

As the world leader in renewable energy growth, China is a driving force for other emerging markets. China has recorded the largest increase in the number of solar and wind installations and the total installed capacity for the last 5 years $[3,4]$. China is the only market

* Corresponding author: faminskaya@mail.ru 
with a capacity of over 100 gigawatt of both of these types of energy. The country accounted for more than half of all new solar installations, as well as two-thirds of solar energy production from photovoltaic panels. Eight of the world's top ten solar energy suppliers are based in China, and the three largest Chinese wind energy companies collectively have the largest share of the wind energy market [5,6]. Moreover, China is the only developing country to rank among the top 10 recipients of net cross-border investment and the top 10 investors, with China being the only emerging market country in the latter category [7]. China set a record for net cross-border investment since 2015, and up to the first half of 2017, the country has invested $\$ 2.23$ billion in wind and solar energy in 11 other developing countries thus attracting domestic investment in these industries from 13 countries for a total of US \$ 1.34 billion [8].

Even excluding China, emerging markets are driving the development of renewable energy globally and have the greatest potential for growth, though emerging markets are not ahead of developed markets in terms of the volume of annually commissioned wind and solar capacities $[9,10]$. However, China's share in terms of added capacity in emerging markets has declined since 2016, both for wind and solar. Elsewhere, emerging markets outperform developed markets even without China's performance. Auction prices for solar and wind energy broke recent records in Mexico and the UAE in 2017 [11,12]. These countries also recorded the world's lowest demand price for wind and solar energy. With the help of energy auctions, India was able to become the most competitive renewable energy market in the world as new players entered the competition. India and Turkey doubled their solar capacity in 2017, with India recently raising its already high bar on renewables. The country plans to increase its renewable capacity to $227 \mathrm{GW}$ by 2022 [13]. Over the past two years, all new facilities have been in emerging markets. Countries with the highest rates of RES investment in GDP (including the Marshall Islands, Rwanda, Solomon Islands, Guinea-Bissau and Serbia) are also emerging markets. Finally, a huge opportunity for the development of renewable energy is given by the African territories, lying to the south of the Sahara - the largest market in the world not yet covered with electricity. For population groups living in regions with a low population density and highly isolated from power grids, the best solution would be solar installations for households, which allow paying for consumed electricity only [14].

According to the International Energy Agency, in the next two decades, most people without access to electricity will be getting it via distributed photovoltaic solar power plants and micro-grids. Developed countries have already benefited from market and product developments that originally emerged in developing countries. As an example, auctions for the sale of renewable energy supplies are a trend driven primarily by emerging markets, resulting in a sharp drop in renewable energy prices worldwide [15]. Some solar and wind energy products targeted at emerging markets are now being introduced to developed markets because of a "reverse innovation" process. Thus, micro-power grids designed to electrify areas not served by traditional power grids have found application in remote mines for developed countries. Consequently, corporations are getting more powerful in facilitating technology transfer between developed and developing countries that are adopting renewable energy sources.

\section{Materials and methods}

The data used for this paper were taken from the reports on various procurement tools employed by corporations, purchasing renewable energy in new ways, involving participants from an increasing number of industries. As far as corporations are concerned about procurement quality, Power Purchase Agreements (PPAs) are becoming the preferred instrument [16]. Such PPEs provide an optimal opportunity to obtain additional capacity, 
while being available for the most part only to large companies. Meanwhile, there has been a trend to aggregate companies to enhance access to this tool for smaller players as well. The largest companies set goals for the introduction of RES into their supply chains, and therefore, encourage that smaller players purchase RES.

Currently, corporations produce or purchase renewable energy, hence, a number of procurement instruments can be used at different scales. One of the most widely used tools employed by 57 countries is the certificate. The certificate certifies that a company has met mandatory requirements or voluntary targets in the field of renewable energy. The certificate does not reflect the full cost of using RES and does not always provide the possibility of obtaining additional benefits in the future. Another tool is green tariffs that is available in 39 countries (mainly European), but they are the least used and transparent instrument of all. In 2017 corporations in 10 countries signed agreements to purchase a record $5.4 \mathrm{GW}$ of renewable energy. This record had been broken by a wide margin, with $7.2 \mathrm{GW}$ of renewable energy purchased in 28 markets worldwide by the end of July 2018 [17]. PPEs offer more value-added benefits and greater cost savings compared to certificates and green tariffs, as well as compared to the cost of electricity from traditional sources. However, for smaller companies, this tool is less available. All instruments mentioned above are available in North America and most European countries. These developed countries continue to be the leading markets for corporate electricity purchases. Situation in other countries (such as Russia) might be different [18].

However, companies in other sectors are also increasing their purchases of renewable energy, and emerging markets are helping to strengthen this trend. Emerging markets such as Brazil, India and Mexico are also offering a full range of renewable energy tools and are showing an increase in renewable energy purchases from international and local companies.

\section{Results and discussions}

Many oil and gas companies have already accumulated significant experience in implementing projects in mature markets in Europe and the United States.

The RES market is developing unevenly around the world and has varying degrees of maturity in developed and developing countries. Various regions have their own RES growth drivers. The strategy for the participation of oil and gas companies in renewable energy projects largely depends on the regions in which they are represented (see Figure 1). As a rule, the countries that are leaders in the development of renewable energy sources are states that are limited in their own resources of fossil fuels.

The development of renewable energy for them is a way to ensure energy security and compliance with the requirements of the Kyoto Protocol, which limits the level of emissions when using solid fuel sources. In many countries, the development of renewable energy sources becomes part of a long-term state strategy; therefore, measures to support the development of renewable energy sources are adopted at the state level, which contributes to the growth of attractiveness (including profitability) and the active implementation of renewable energy projects by international companies.

Renewable energy projects are becoming part of the development strategy of the largest oil and gas companies, which is supported by the volume of their investments.

Independent and state-owned European oil and gas companies retain their historically established global leadership in the development of renewable energy sources. Table 1 that follows below provides an overview of the global investments into renewable energy by a selected group of countries. 


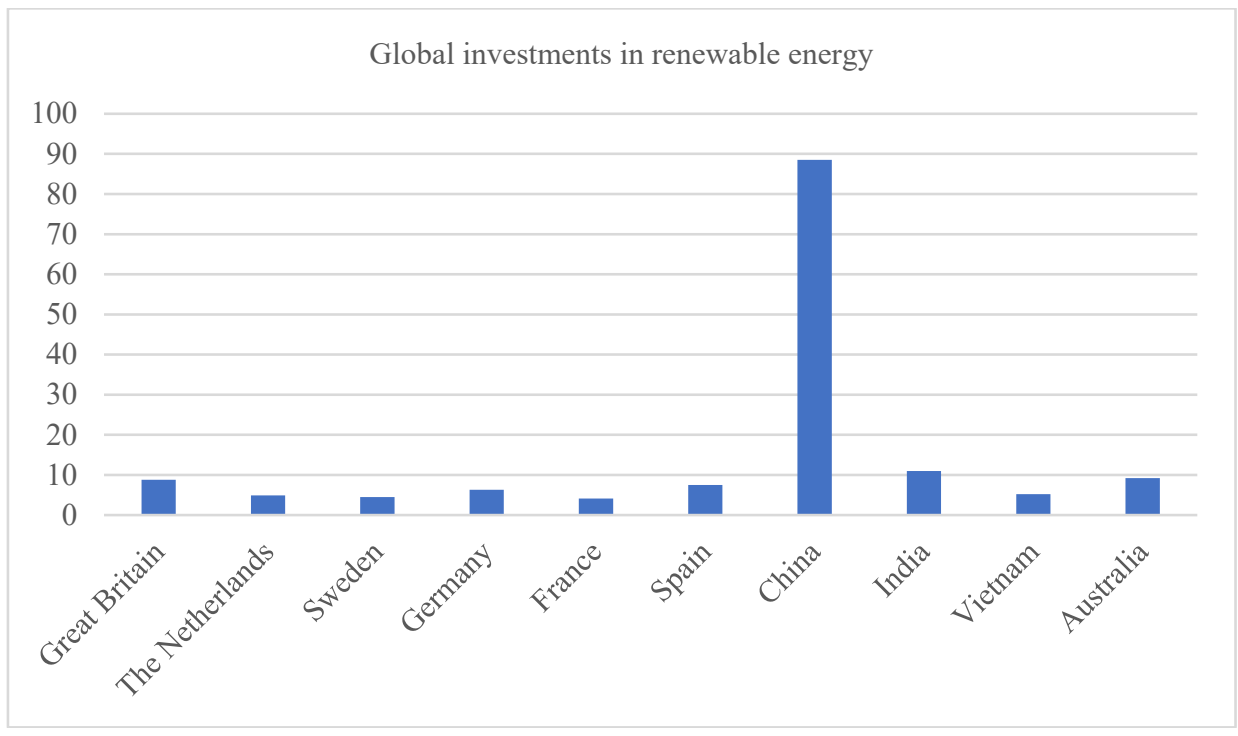

Fig. 1. Global investments in renewable energy (in billions of U.S. dollars) [19]

Companies such as Shell, Total, ENI, Equinor and BP are the largest investors in renewable energy projects. $3-5 \%$ of the total investments of these companies were on renewable energy sources and related projects as part of the energy transition strategy in 2018 as an average.

Table 1. Renewable energy investments of major gas and oil companies [20]

\begin{tabular}{|l|l|l|l|}
\hline $\begin{array}{l}\text { Oil and gas } \\
\text { company }\end{array}$ & Planning horizon & $\begin{array}{l}\text { Investments in RES } \\
\text { (billion US dollars) }\end{array}$ & $\begin{array}{l}\text { Share in total company } \\
\text { investments (\%) }\end{array}$ \\
\hline Shell & $2021-2025$ & $2-4$ & 8 \\
\hline ENI & $2018-2020$ & 1.1 & 3.6 \\
\hline Total & $2019-2023$ & $1.5-2$ & $10-15$ \\
\hline Equinor & $2020-2025$ & $0.7-1.5$ & $\mathrm{n} / \mathrm{a}$ \\
\hline Saudi Aramco & Up till 2030 & $30-50$ & 1.7 \\
\hline
\end{tabular}

In the near future, large national companies from oil and gas producing countries may compete with international giants, who are shaping a long-term vision around clean energy. The state-owned company Sonatrach in Algeria plans to increase its solar activities. Asian companies Pertamina (Indonesia) and Sinopec (China) claimed they are ready to continue the development of renewable energy sources. Oman national company PDO said that up to $20 \%$ of its revenues in 10 years will be coming from new businesses such as solar, wind and wave energy.

Oil and gas companies have not yet proposed a single business model in the field of renewable energy; each company forms a strategy that reflects its long-term vision and the current state of its core business. By the early 2030s, Shell intends to become a leader in the world of power generation, including the implementation of renewable energy projects. By integrating the entire value chain from generation to distribution and offering B2B and B2C products, the company plans to maximize its return on investment. Total, on the contrary, adheres to the asset-light model by gradually reducing its share in renewable energy projects from the development stage to commissioning (up to 50\%). During the operational phase, the company remains the main operator. 


\section{Conclusions}

The development of solar and wind energy has recently reached new frontiers. Renewable energy is no longer just a popular, but a preferred source of energy supply. As alternative energy sources achieve price and performance parity with traditional sources around the world, demonstrate the ability to improve grid efficiency and strengthen their competitiveness with new technologies, the barriers to their adoption are gradually disappearing. Solar and wind energy are already some of the cheapest energy sources in the world and have significant potential for further development, as a lot of trends have not yet been fully implemented.

The cost of renewable energy is declining, and the successful integration of renewables is well under way, supported by the development of technologies that provide even greater efficiency and empower companies. Meanwhile, the demand for renewable energy sources is steadily growing. Today, solar and wind energy can almost completely satisfy three key consumer needs: stability of energy supply, affordable cost and environmental friendliness. In markets leading the renewable energy sector, such as Denmark, supranational, national and local interests are aligned with these requirements. In other countries, such as the United States and Australia, where national governments are reluctant to participate in global carbon reduction initiatives, cities, communities and corporations have taken on the most important roles in these endeavors. They are stepping up their efforts to fill the vacuum, and therefore the demand for renewable energy continues to grow.

Finally, emerging markets, which will see the most noticeable increases in electricity demand with further development in electrification, are pursuing a leading position in the solar and wind energy market. This means that the case for renewable energy is stronger than ever before.

\section{References}

1. IRENA (2018), Renewable capacity statistics 2018, International Renewable Energy Agency (IRENA), Abu Dhabi

2. E. Lisin, W. Strielkowski, V. Chernova, A. Fomina, Energies, 11(12), 3284 (2018)

3. Peidong, Y. Yanli, Shi jin, Z. Yonghong, W. Lisheng, L. Xinrong, Renewable and Sustainable Energy Reviews, 13(2), 439 (2009)

4. W. Liu, H. Lund, B. Vad Mathiesen, X. Zhang, Applied Energy, 88(2), 518 (2011)

5. F. Dinçer, Renewable and Sustainable Energy Reviews, 15(1), 713 (2011)

6. T.M. Razykov, C.S. Ferekides, D. Morel, E. Stefanakos, H.S. Ullal, H.M. Upadhyaya, Solar Energy, 85(8), 1580 (2011)

7. S. Gopal, J. Pitts, Z. Li, K.P. Gallagher, J.G. Baldwin, W.N. Kring, Energies, 11(10), 2804 (2018)

8. G. Ragosa, P. Warren, Journal of Cleaner Production, 235, 854 (2019)

9. A. Elia, M. Kamidelivand, F. Rogan, B. Ó Gallachóir, Renewable and Sustainable Energy Reviews, 138, 110488 (2021)

10. R. Vanickova, Marketing and Management of Innovations, 2, 56-67 (2020)

11. A.J. Al-Yasiria, M.A. Alib , R.S. Alic , H.N. Bekheet, International Journal of Innovation, Creativity and Change, 11(3), 376 (2020)

12. N. Martinez, N. Komendantova, Energy Policy, 145, 111744 (2020)

13. Baris Memduh Eren, Nigar Taspinar, Korhan K. Gokmenoglu, Science of The Total Environment, 663, 189 (2019)

14. A.K. Aliyu, B. Modu, C.W. Tan, Renewable and Sustainable Energy Reviews, 81(2), $2502(2018)$ 
15. A. K. Nasr, M. K. Kashan, A. Maleki, N. Jafari, H. Hashemi, Entrepreneurship and Sustainability Issues, 7(3), 2526-2541 (2020)

16. B. Tranberg, R. T. Hansen, L. Catania, Energy Economics, 85, 104567 (2020)

17. B. Usher, Renewable Energy: a primer for the twenty-first century (2019)

18. A. Kuzmin, E. Volkova, A. Fomina, International Journal of Energy Economics and Policy, 9(1), 130-136 (2019)

19. Statista, https://www.statista.com/statistics/186818/north-american-investment-insustainable-energy-since-2004 (2021)

20. D. Bogdanov, A. Gulagi, M. Fasihi, C. Breyer, Applied Energy, 283, 116273 (2021) 